\title{
Osteoarthritis of the hip and osteoporosis of the proximal femur*
}

\author{
C Cooper, P L Cook, C Osmond, L Fisher, M I D Cawley
}

\begin{abstract}
A negative association has been reported between osteoarthritis and osteoporosis. There are, however, few population based data to support this association. In this study the bone density in the upper femur was compared with the presence and severity of hip osteoarthritis in 314 subjects undergoing radiography for non-skeletal indications. There was a statistically significant negative association between the two disorders. This relation may reflect differences in the cause of these two major musculoskeletal conditions.
\end{abstract}

Osteoarthritis and osteoporosis are two common, age related musculoskeletal disorders associated with considerable morbidity and mortality. The relation between the two conditions remains unclear, however. Evidence from case series suggests that osteoarthritis is uncommon in patients who have sustained hip fractures. ${ }^{1-3}$ In contrast, studies measuring bone density at various skeletal sites have failed to detect consistent differences between patients with osteoarthritis and healthy control subjects. ${ }^{4-8}$

As osteoarthritis is a heterogeneous condition and bone density varies at different skeletal sites the relation between the two may differ according to the anatomical site examined. We report here the relation between osteoarthritis and osteoporosis in the hip, a major site of disease in both disorders, using a series of radiographs selected to represent the general population.

\section{Patients and methods}

The study sample comprised 314 men and women aged 50 years and over, who consecutively attended the radiology department of Southampton General Hospital and who were undergoing radiography for non-skeletal indications. Patients who had undergone hip surgery (four) or previously sustained hip fractures (one) were excluded. The radiographic examinations made on these subjects were intravenous pyelography (79\%), plain abdominal radiographs $(17 \%)$, barium meals $(2 \%)$, and barium enemata $(2 \%)$. In all 314 subjects a single additional radiograph of the right upper femur was obtained in 10 degrees of internal rotation.

Bone density in the proximal femur was assessed from the hip radiographs by a single trained observer (CC) using the Singh grading system of the femoral neck trabecular pattern. ${ }^{9}$ This pattern is characterised on a six point scale from grade 6 , where all the major groups of trabeculae are present, to grade 1 , in which only the minor compressive group is visible. For subsequent analysis the grades were amalgamated as follows: grades 5 and 6 (normal), grades 3 and 4 (mild osteoporosis), and grades 1 and 2 (marked osteoporosis). The repeatability of this grading method in our hands has been previously published. ${ }^{10}$

The degree of osteoarthritis in the hip was evaluated according to the Empire Rheumatism Council criteria. ${ }^{11}$ This uses a series of standard radiographs against which the sequential appearance of joint space narrowing, osteophytosis, subchondral sclerosis, cyst formation, and femoral head deformity can be compared. Three levels of osteoarthritis were defined: grade 0 (normal), grades 1 and 2 (mild), and grades 3 and 4 (marked). As the repeatability of this grading method has not been rigorously assessed, all radiographs were independently viewed by two observers (PLC and LF) and discrepancies were adjudicated by a third (MIDC). Within and between observer variation were formally assessed. For within observer variation a set of 100 study radiographs selected to represent a range of osteoarthritis was presented to one of the observers (LF) on two occasions separated by three weeks. For between observer variation a separate series of 100 radiographs was assessed by the two initial observers in the study.

To reduce observer bias separate observers graded each condition. The grading of osteoarthritis was done after that of osteoporosis, and by observers who had not taken part in the latter assessment.

The association between osteoporosis and osteoarthritis in the study sample was assessed by the $\chi^{2}$ test. Adjustments for age and sex were made by stratification for these two variables.

\section{Results}

Table 1 shows the age and sex distribution of the study sample. Approximately equal numbers of subjects fell into each age category: $50-64,65-74$, and 75 years and above. In each age category there were more men than women, reflecting the demographic characteristics of the group at this radiology department who were undergoing intravenous urography.

Table 1 Age and sex distribution of study sample. Number (percentage) of patients is shown

\begin{tabular}{llll}
\hline Age group & $\begin{array}{l}\text { Men } \\
(n=210)\end{array}$ & $\begin{array}{l}\text { Women } \\
(n=104)\end{array}$ & $\begin{array}{l}\text { Total } \\
(n=314)\end{array}$ \\
\hline $50-64$ & $66(31)$ & $34(33)$ & $100(32)$ \\
$65-74$ & $68(32)$ & $40(38)$ & $108(34)$ \\
$75+$ & $76(36)$ & $30(29)$ & $106(34)$ \\
\hline
\end{tabular}


Table 2 Reproducibility of grading of hip osteoarthritis in 100 study radiographs

\begin{tabular}{|c|c|c|c|c|}
\hline & \multirow{2}{*}{ 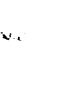 } & \multicolumn{3}{|c|}{ Osteoarthritis grade } \\
\hline & & 0 & $1+2$ & $3+4$ \\
\hline \multicolumn{2}{|c|}{ Within observer variation } & \multicolumn{3}{|c|}{ First reading } \\
\hline Second reading & $\begin{array}{r}0 \\
1+2 \\
3+4\end{array}$ & 52 & $\begin{array}{r}5 \\
25 \\
1\end{array}$ & $\begin{array}{r}2 \\
12\end{array}$ \\
\hline \multicolumn{5}{|c|}{ Kappa $=0.81(95 \%$ confidence interval 0.66 to 0.96$)$} \\
\hline Second observer & $\begin{array}{r}0 \\
1+2 \\
3+4\end{array}$ & $\begin{array}{r}36 \\
13 \\
1\end{array}$ & $\begin{array}{r}9 \\
22 \\
5\end{array}$ & $\begin{array}{r}1 \\
3 \\
10\end{array}$ \\
\hline
\end{tabular}

Kappa $=0.48$ (95\% confidence interval 0.33 to 0.53 ).

Table 3 Association between osteoarthritis and osteoporosis in 314 hip radiographs

\begin{tabular}{cllll}
\hline $\begin{array}{l}\text { Grade of } \\
\text { osteoarthritis }\end{array}$ & \multicolumn{4}{l}{ Grade of osteoporosis (Singh) } \\
\cline { 2 - 5 } & $5+6$ & $3+4$ & $1+2$ & $A l l$ \\
\hline 0 & 62 & 88 & 33 & 183 \\
$1+2$ & $(81 \cdot 9)^{*}$ & $(78 \cdot 8)$ & $(22 \cdot 3)$ & \\
& 53 & 39 & 1 & 93 \\
$3+4$ & $(43 \cdot 3)$ & $(40 \cdot 7)$ & $(9 \cdot 0)$ & \\
& 28 & 9 & 1 & 38 \\
All & $(17 \cdot 8)$ & $(16 \cdot 5)$ & $(3 \cdot 7)$ & \\
& 143 & 136 & 35 & 314
\end{tabular}

*Figures in parentheses are expected numbers in each group, calculated assuming no association between the two disorders.

Table 2 shows the repeatability of the radiographic assessment of osteoarthritis in the sample of 100 radiographs. Within observer variation was low, with concordance between first and second readings in 89 of the radiographs and adjacent discordance in the remaining 11 . The within observer kappa $(x)$ statistic was 0.81 ( $95 \%$ confidence interval 0.66 to 0.96 ). Between observer variation was greater, with concordance in only 68 of the radiographs, giving a $x$ statistic of 0.48 (95\% confidence interval 0.33 to 0.53 ).

Table 3 shows the relation between grade of osteoporosis and of osteoarthritis in the study sample. In each group the expected number of observations is given in parentheses, assuming no relation between the two variables in each age and sex stratum. Comparison between the observed and expected numbers shows a dearth of subjects who had both conditions and an excess of those with one or other condition. This negative association between the disorders was statistically significant $\left(\chi^{2}=31 \cdot 54, \mathrm{df}=4\right.$, $\mathrm{p}<0.001$ ) and remained so after stratification for age and sex. When the sexes were analysed separately the negative association was found in both men and women.

\section{Discussion}

We compared the degree of osteoarthritis in the hip joint with bone density in the femoral neck in a series of hip radiographs selected to represent the population. Our results suggest a statistically significant negative association between osteoarthritis and osteoporosis at this site.

Bone density was measured using an index of the upper femoral trabecular pattern. We have previously assessed the validity and reproducibility of this technique in our hands. ${ }^{10}$ Although clearly prone to error in individual subjects, the method is sufficiently reproducible for use in epidemiological studies. The grading of osteoarthritis in the hip joint used the Empire Rheumatism Council grading system. This is the most widely used system for grading osteoarthritis at various skeletal sites. ${ }^{12} 13 \mathrm{We}$ found within observer variation to be low with this grading system, but between observer variation to be substantially higher. We therefore used an arbitrating observer to adjudicate on radiographs for which the initial observers' readings were discrepant.

Although the study sample was confined to subjects undergoing radiography for nonskeletal indications, the prevalence of osteoarthritis and osteoporosis was found to be similar to that in published population surveys of these two conditions, ${ }^{14} 15$ suggesting that the negative association between the two variables did not arise from some unforeseen selection bias.

The absence of hip osteoarthritis in patients with femoral neck fractures was initially reported two decades ago. ${ }^{1}$ It has been confirmed in subsequent case series, ${ }^{2}$ as well as in a radiological case-control study. ${ }^{3}$ The results of studies of bone density in patients with osteoarthritis have been conflicting, however. ${ }^{4-8}$ Some of the discrepancy in these results might be explained by differences in the definition of osteoarthritis, variable standardisation of bone density measurements for body build, and the well recognised discordance between bone density measurements at different skeletal sites. ${ }^{16}$ Our results support those of the only previously published population based study to examine the association between these two conditions. In a random population sample from Jerusalem Pogrund et al reported that osteoarthritis and osteoporosis coexisted in only $0.5 \%$ of the 641 subjects. ${ }^{15}$

Why might this negative association between osteoarthritis and osteoporosis exist? Individual risk factors for osteoporosis include oestrogen deficiency, physical inactivity, and low body weight. ${ }^{17}$ These factors might be protective against osteoarthritis. Relative oestrogen excess has been suggested as a factor in the development of generalised osteoarthritis. ${ }^{18}$ The hip joint is not as commonly affected in this clinical subset of osteoarthritis as the hand and knee, however. ${ }^{19}$ Excess weightbearing physical activity is also a potential risk factor for osteoarthritis, which might theoretically reduce the risk of osteoporosis.

The potential role of body build in explaining the noted relation between osteoarthritis and osteoporosis warrants further consideration. Obesity is a reported risk factor for generalised osteoarthritis but does not seem to influence the risk of hip osteoarthritis. ${ }^{20}$ Adiposity is known to protect against osteoporosis at various skeletal sites, but the influence of body mass index on the trabecular architecture of the upper femur has never been specifically considered. The body build of the subjects in our study was unfortunately not available, and the possibility 
that the noted negative association between osteoarthritis and osteoporosis is a reflection of differences in body mass remains a real one.

An alternative interpretation of the negative association between the two conditions is that they represent variable responses of subchondral bone to mechanical stress. ${ }^{21}$ In osteoporosis the osteoblastic response is blunted, whereas in osteoarthritis it is accentuated. At a more local level, one of the early features of osteoarthritis of the hip is osteophyte formation with buttressing at the medial cortical margin of the femoral neck. A strong relation has previously been seen, in the radiographs of patients with osteoporosis and osteoarthritis who came for surgery, between the Singh grade and the thickness of the calcar femorale. ${ }^{10}$ Thus localised femoral neck bone remodelling might also contribute to our findings.

In conclusion, our results suggest a negative association between osteoarthritis of the hip and osteoporosis of the upper femur in the general population. Further exploration of this negative association might yield clues to the cause of these two age related skeletal conditions.

We thank the consultants and staff of the department of radiology, Southampton General Hospital, for their assistance in taking the necessary radiographs.

1 Foss M V L, Byers P D. Bone density, osteoarthrosis of the hip and fracture of the upper end of the femur. Ann Rherm hip and fracture of the

2 Solomon L, Schnitzler C M, Browett J P. Osteoarthritis of the hip: the patient behind the disease. Ann Rherum Dis 1982; 41: 118-25.

3 Weintroub S, Papo J, Ashkenazi M, Tardiman R, Weissman $S \mathrm{~L}$, Salama R. Osteoarthritis of the hip and fractures of the proximal end of the femur. Acta Orthop Scand 1982; 53: $261-4$
4 Reid D M, Kennedy N S J, Smith M A, Tothill P, Nuki G. Bone mass in nodal primary generalised osteoarthrosis. Ann Rhewom Dis 1984; 43: 240-2.

5 Price T, Reeve J, Mitchell R, Hesp R. Bone density in generalised osteoarthritis. Ann R heum Dis 1983; 42: 227-8. 6 Cooper C, Poll V, Mclaren M, Daunt S O'N, Cawley M I D. Alterations in appendicular skeletal mass in patients with rheumatoid, psoriatic, and osteoarthropathy. Ann Rhewm Dis 1988; 47: 481-4.

7 Roh Y S, Dequeker J, Mulier J C. Bone mass in osteoarthrosis measured in vivo by photon absorption. $\mathcal{f}$ Bone foint Surg [Am] 1974; 56: 587-91.

8 Alhava $\mathbf{E}$ M, Kettunen $\dot{K}$, Karjalainen P. Bone mineral in patients with osteoarthrosis of the hip. Acta Orthop Scand 1975; 46: 709-15.

9 Singh $M$, Nagrath A R, Maini P S. Changes in trabecular pattern of the upper end of the femur as an index of osteoporosis. F Bone foint Surg [Am] 1970; 52: 457-67.

10 Cooper C, Barker D J P, Hall A J. Evaluation of the Singh index and femoral calcar width as epidemiological methods index and femoral calcar width as epidemiological methods 1986; 37: 123-5.

11 Kellgren J H, Jeffrey M R, Ball J. Atlas of standard radiographs. Vol II. The epidemiology of chronic rheumatism. Oxford: Blackwell Scientific, 1963.

12 Kellgren J H, Lawrence J S. Radiological assessment of osteoarthrosis. Ann Rheum Dis 1957; 16: 494-502.

13 Van Saase J L C M, Van Romunde L K J, Cats A, Vandenbroucke J P, Valkenburg H A. Epidemiology of osteoarthritis: Zoetermeer survey. Comparison of radioostear hricis: Zoeter in a Dutch population with other populations. Ann Rhewn Dis 1989; 48: 271-80.

14 Lawrence J S, Bremner J M, Bier F. Osteoarthrosis. Prevalence in the population and relationship between Prevalence in the population and relationship between symptom.

15 Pogrund H, Rutemberg M, Makin M, Robin G, Menczel J, Steinberg R. Osteoarthritis of the hip joint and osteoporosis: adiological study in a random population sample in Jerusalem. Clin Orthop 1982; 164: 130-5.

16 Dequeker J. The relationship between osteoporosis and osteoarthritis. Clin Rherem Dis 1985; 11 : 271-96.

17 Cooper C. Osteoporosis - an epidemiological perspective. $\mathcal{f} R$ Soc Med 1989; 82: 753-7.

18 Spector T D, Campion G D. Generalised osteoarthritis: a hormonally mediated disease. Ann Rheum Dis 1989; 48: hormon.

19 Cushnaghan J, Dieppe P. A long term study of 500 patients with osteoarthritis: disease patterns [Abstract]. $\mathrm{Br} \mathcal{F}$ Rheumatol 1988; 27 (suppl 1): 11

20 Hartz A J, Fischer M E, Bril G, et al. The association of obesity with joint pain and osteoarthritis in the HANES data. Foumal of Chronic Diseases 1986; 39: 311-9.

21 Radin E L, Paul I L, Rose R M. Role of mechanical factors in pathogenesis of primary osteoarthritis. Lancet 1972; i: 519-21. 